\title{
Os impactos do processo de internacionalização sobre o Sistema de Controle Gerencial: o caso da empresa Localiza
}

\section{Simone das Neves Fialho, Josir Simeone Gomes}

Universidade d

UNIGRANRIO

Programa de Mestrado e Doutorado

Universidade do Grande Rio

O objetivo deste artigo foi estudar os impactos do processo de internacionalização sobre o sistema de controle gerencial da empresa Localiza S.A. Conforme literatura sobre o tema, o processo de internacionalização, bem como sua extensão, impele às organizaçóes o desafio de transferir o Controle Gerencial para além das fronteiras nacionais. Tal abordagem inspira a possibilidade de a internacionalização impactar os Sistemas de Controle de Gestão. Para tanto, adotou-se a pesquisa exploratória-descritiva. A coleta de dados utilizou pesquisa bibliográfica, documental e estudo de caso. Dentre os documentos coletados, destacam-se duas entrevistas, do CEO da Localiza e do Diretor de Franquias da empresa. As entrevistas já se encontravam disponibilizadas em meios digitais e foram realizadas nos meses de agosto de $2020 \mathrm{e}$ agosto de 2009, respectivamente. Foram coletados apenas dados secundários, não obstante o acesso completo ao conteúdo das entrevistas referenciadas. Os resultados obtidos indicaram que a internacionalização não promoveu mudanças significativas no sistema de controle gerencial da empresa, em consonância com literatura não majoritária sobre o tema. Entretanto, observou-se grandes mudanças no controle gerencial a partir do processo de expansão da empresa como um todo, as quais, notadamente, impactaram o desempenho das franquias internacionais.

Palavras-chave: controle gerencial, internacionalização, Localiza

\section{Los impactos del proceso de internacionalización en el sistema de control degestión: el caso de la empresa Localiza}

El objetivo de este artículo es estudiar los impactos del proceso de internacionalización en el sistema de control de gestión de Localiza S.A. Según la literatura sobre el tema, el proceso de internacionalización, así como su extensión, desafía a las organizaciones a trascender el control de gestión más allá de las fronteras nacionales. Este enfoque implica la posibilidad de que la internacionalización afecte a los sistemas de control de gestión. Para realizar la investigación, se tomó una metodología exploratoria-descriptiva. Para la recolección de datos, se utilizó la investigación bibliográfica, la documentación y el estudio de casos. Entre los documentos recogidos, destacan dos entrevistas: una al consejero delegado de Localiza y otra al director de Franquicias de la empresa, realizadas en agosto de 2020 y 2009 respectivamente. Las entrevistas ya estaban publicadas en medios digitales. Por ello, solo se tuvieron que recoger datos secundarios. Siguiendo la línea de la mayoría de la literatura sobre el tema, los resultados obtenidos indicaron que la internacionalización no promovió cambios significativos en el sistema de control de gestión de la empresa. Sin embargo, se observaron importantes cambios en el control de la gestión a partir del proceso de expansión de la empresa en su conjunto, lo que repercutió notablemente en los resultados de las franquicias internacionales.

Palabras clave: control de gestión, internacionalización, Localiza S.A 


\section{The impacts of the internationalization process on the Management Control System: the case of the Loca- liza company}

The objective of this article was to study the impacts of the internationalization process on the management control system of Localiza S.A. According to the literature on the subject, the internationalization process, as well as its extension, pushes organizations to the challenge of transferring Management Control beyond national borders. Such approach inspires the possibility of internationalization impacting the Management Control Systems. For this, exploratory-descriptive research was adopted. The data collection used bibliographic research, documentation and case studies. Among the documents collected, two interviews stand out, of the CEO of Localiza and the Director of Franchises of the company. The interviews were already available in digital media and were conducted in August 2020 and August 2009, respectively. Only secondary data were collected, despite full access to the content of the referenced interviews. The results obtained indicated that the internationalization did not promote significant changes in the company's management control system, in line with nonmajoritarian literature on the theme. However, it was observed great changes on management control from the expansion process of the company as a whole, which notably impacted the performance of international franchises.

Keywords: management control, internationalization, Localiza

\section{Introduçáo}

O fenômeno do processo de internacionalização das empresas brasileiras é bastante recente, cujos primeiros relatos de expansão para mercados além território nacional remetem à década de 1990. Segundo Guerra e Senhoras (2015), "a internacionalização de empresas é um fenômeno caracterizado pela prática contínua de qualquer operação internacional por parte de uma empresa, variando desde a prática de simples exportação de produtos a total internacionalização da produção" (p. 15). A edição histórica do estudo "Trajetórias FDC de Internacionalização das Empresas Brasileiras', publicado pela Fundação Dom Cabral (FDC) em 2020, retrata a intensificaçáo do processo de internacionalização das empresas brasileiras nos anos de 1990 e 2000, sendo a América do Sul a região preferida, ao contabilizar a entrada de 63 empresas.

Alguns fatores são elencados como impulsionadores para o processo de internacionalização de uma empresa, como a busca por expansáo dos negócios e/ou exploração de novos mercados, a necessidade de otimização de recursos e a consolidação de suas operaçóes (Dunning,
1988, 2000; Johanson \& Vahlne, 2009). Sobre as decorrências do processo de internacionalização, a literatura aponta para possibilidades distintas. Segundo Anthony e Govindarajan (1998), os processos de planejamento e controle de uma empresa multinacional, em princípio, permanecem semelhantes às de uma empresa nacional, ainda que necessitem ser especificamente projetados para atender o novo contexto.

Por outro lado, Dyment (1987), a partir da distinção entre o conceito de empresa multinacional tradicional e de empresa global, salienta que o controle gerencial se revela um assunto mais complexo. A dualidade advinda de tais entendimentos, bem como possíveis correlaçóes entre as abordagens adotadas no processo de internacionalização de empresas e os impactos daquele processo sobre os sistemas de controle gerencial, consiste na lacuna de conhecimento para cujo preenchimento esta pesquisa almeja contribuir. $\mathrm{O}$ diferencial deste estudo, portanto, reside em inserir no escopo da análise dos impactos no controle gerencial, gerados a partir do processo de internacionalização, a análise do próprio processo de internacionalização. 
Nesse contexto, a pesquisa torna-se relevante ao proporcionar o levantamento de informaçóes e características da organização que venham subsidiar estudos futuros que abordem a existência de possível correlaçâo entre as premissas que norteiam o processo de internacionalização e a forma como as empresas organizam seus sistemas de controle gerencial após tal processo. Assim, o conhecimento produzido contribuirá tanto como incremento ao arcabouço teórico de controle gerencial quanto como orientação estratégica a nível organizacional. Para tanto, adotar-se-á uma pesquisa exploratória-descritiva, para cuja coleta de dados adotará pesquisa bibliográfica, documental e estudo de caso, tudo para o alcance do propósito desta pesquisa, que será analisar os impactos do processo de internacionalização da empresa Localiza sobre seu Sistema de Controle de Gestão. Nesse escopo, este artigo está organizado a partir da construção de um referencial teórico sobre as abordagens de controle gerencial, o processo de internacionalizaçáo de empresas e seus impactos sobre os sistemas de controle gerencial. Posteriormente, será apresentada a metodologia, a análise dos dados e a discussão dos resultados.

\section{Referencial Teórico}

\subsection{Abordagens sobre controle Gerencial}

Segundo Macintosh (1994):

O termo controle pode ser considerado um dos mais controversos de nosso tempo. Metade das pessoas do mundo imagina o controle como coerção e opressão e que deveriam ter muito pouco do mesmo. Já a outra metade reclama por mais controle, percebendo-o como muito importante para regular as relaçóes entre as pessoas e organizaçóes e que sua ausência significaria o caos (p. 1).

O tema controle de gestão experimentou grande expansão conceitual a partir da década de 1950. Desse período até a década de 1970, novos enfoques surgiram, incorporando outros conceitos, muitos emprestados de outras áreas, como a economia, sociologia e psicologia (Gomes \& Salas, 2001).

Segundo Gomes e Salas (2001), "controle de gestão refere-se ao processo que resulta da inter-relação de um conjunto de elementos internos (formais e informais) e externos à organização que influem no comportamento dos indivíduos que formam parte da mesma” (p. 23). Para Anthony (1965), controle de gestão "é o processo pelo qual os administradores asseguram que os recursos sejam obtidos e usados eficaz e eficientemente" [tradução nossa ${ }^{1}$ ] (p. 17). Nesse contexto, o controle de gestáo diz respeito à combinação de atividades de planejamento e controle, e está relacionado à satisfação das motivaçóes individuais. $\mathrm{O}$ autor apresenta um modelo pragmático do processo de controle. Seu foco, no tocante à estrutura organizacional, está fortemente baseado no conceito de centros de responsabilidade e na avaliação de desempenho. Sobretudo, considera que o objetivo de um sistema de controle gerencial é o goal congruence - onde as metas pessoais dos funcionários devem ser compatíveis com os objetivos da organização.

Gomes e Salas (2001) ressaltam que o controle é fundamental para assegurar que o comportamento dos indivíduos esteja alinhado aos objetivos traçados pela organização, bem como para que contribuam com o alcance das estratégias, planos, programas e operaçôes,

\footnotetext{
1 "The process by which managers ensure that resources are obtained ans used effectively and efficiently in the accomplishment of the organization's objectives" (Anthony, 1965, p. 17).
} 
sustentando e melhorando a posição competitiva da organização. Para Lorange e Morton (1974), o objetivo principal do sistema de controle é auxiliar a administração na consecução dos objetivos da organização através de uma estrutura formal que permita: a identificação de variáveis de controle pertinentes, desenvolvimento de bons planos de curto prazo e o diagnóstico de desvios. $\mathrm{Na}$ abordagem desses autores, a ênfase recai sobre o ambiente e as demandas ambientais sobre a dinâmica organizacional, ressaltando que são as características do ambiente que condicionam as organizacionais.

Em seu plano de referência, Hofstede (1975) retrata o controle como um sistema em si mesmo, rejeitando o modelo cibernético e apresentando o controle homeostático. Para o autor, a implantação desse sistema de controle de gestão homeostático requer mudanças significativas na filosofia de controle, já que está fundamentado em uma visão mais ampla de um processo sócio-psicológico diferente dos sistemas tradicionais. Cerca de duas décadas depois, Flamholtz (1996) reitera que a preocupação de todas as organizações reside na canalização de esforços humanos em vista do alcance dos objetivos organizacionais. Nesse sentido, cabe às organizaçóes influenciar o comportamento das pessoas para que cumpram os objetivos propostos.

Num contexto mais recente, Malmi e Brown (2008) definem o Controle Gerencial como "sistemas, regras, práticas, valores e gestão de outras atividades implantadas de forma a direcionar o comportamento dos colaboradores" (p. 290). Conforme pode-se depreender, ao percorrer a série histórica de conceitos sobre o controle gerencial, verifica-se que a premissa central do tema permanece: deve ser capaz de impulsionar o comportamento dos integrantes da organização de forma alinhada ao alcance dos objetivos organizacionais. Trata-se, pois, de uma abordagem interna.
Merchant e Van der Stede (2017) esclarecem que, enquanto o controle estratégico se concentra no ambiente externo, o controle de gestáo concentra-se em atividades internas que influenciam o comportamento dos funcionários de acordo com alvos predefinidos. Para Flamholtz (1996), um Sistema de Controle Organizacional pode ser definido como: "um conjunto de mecanismos, processos e técnicas que se destinam a aumentar a probabilidade de que as pessoas vão se comportar de maneiras que levam para a realização de objetivos organizacionais" (p. 6).

Segundo o autor, para que os sistemas de controle motivem as pessoas a se comportar de maneira consistente com as metas organizacionais, tais sistemas devem executar quatro tarefas relacionadas: ser capaz de motivar as pessoas a tomar decisões e realizar ações que são coerentes com os objetivos organizacionais; sistemas de controle próximos devem integrar os esforços de várias partes diferentes de uma organização; fornecer informaçóes sobre os resultados das operaçóes e desempenho das pessoas (controle com autonomia); e facilitar a implementação de planos estratégicos. Gomes e Salas (2001) salientam que a preferência por determinado sistema de controle gerencial em detrimento a outro é balizado tanto pelas características da organização (relação de propriedade, cultura, estilo dos gerentes/relaçóes interpessoais, grau de descentralização e formalização da atividade), quanto pelo contexto social (caracterizados principalmente pelo grau de dinamismo e pela concorrência). De modo análogo, ressaltam que as características do controle organizacional também restarão influenciadas pelo tipo de contexto social e pelo grau de descentralização. Consideradas aquelas características e fundamentados na combinação dos mecanismos adotados pelas organizaçóes, os autores apresentaram quatro tipos de controle organizacional, retratados na tabela 1 : 


\section{Tabela 1. Tipos de controle organizacional}

\section{Controle familiar}

- Utilizado em empresas, onde a menor dimensão ou a estabilidade do contexto social facilitam o controle mais informal.

- Ênfase nas relaçóes pessoais, liderança de um pai (o fundador líder ou gerente).

- O controle de gestão está baseado na adoção de mecanismos de controle informais, na liderança do gerente, na centralização das decisões, na delegaçấo de autoridade baseada na amizade pessoal e no desenvolvimento de uma cultura que promova a lealdade e a confiança.

- O maior risco deste tipo de controle é que prevaleça a fidelidade ao líder, em detrimento da eficácia e da inovação.

- Cultura organizacional paternalista, condicionada à fidelidade ao líder.

\section{Controle por resultados}

- Utilizado, com mais frequência, em contextos sociais muito competitivos, sendo fortemente baseado em sistemas de controle financeiro.

- Caracterizado pelo elevado grau de descentralização através do estabelecimento de objetivos e ampla utilização de centros de responsabilidade, que são avaliados com base nos resultados apresentados.

- A descentralização aumenta o grau de autonomia, responsabilidade e discricionaridade e, consequentemente, a necessidade de controle.

- Sua principal fragilidade reside no próprio conceito de resultado, relacionado à motivação e à participação das pessoas no processo de definição dos mecanismos de controle a serem adotados para avaliar o desempenho dos centros de responsabilidade.

- Cultura voltada para resultados.

\section{Controle burocrático}

- Próprio de ambientes pouco competitivos e característico de organizaçóes de grande porte, fortemente centralizadas e, normalmente, fechadas para o exterior.

- Controle de gestấo baseado na formalizaçáo da estrutura e do sistema de controle e na centralizaçáo das decisóes.

- Cultura organizacional paternalista e avessa à mudança.

\section{Controle ad-hoc}

- Baseia-se na utilização de mecanismos não formais que promovem o autocontrole.

- É adotado, normalmente, em ambientes muito dinâmicos e de grande complexidade, como os que circundam as organizaçóes de alta tecnologia, design, publicidade, consultoria e outras.

- Desenvolve-se em estruturas bastante descentralizadas, com limitada utilização de medidas financeiras.

- Cultura baseada no individualismo e na busca de consenso.

Fonte: Elaborado pelos autores com base em Gomes e Salas (2001, p. 57-60).

\subsection{O Processo de internacionalizaçáo de empresa}

A internacionalização tem-se revelado um processo gradual e progressivo de desenvolvimento dos negócios de uma organização em contexto territorial diverso do seu de origem e constitui-se em um fenômeno longevo, sob o qual muito tem sido estudado (Goulart, Arruda \& Brasil, 1994). Segundo Barreto e Rocha (2003), a internacionalização pode ser definida como "um processo de crescente envolvimento com operaçóes internacionais" (p. 30). Os autores entendem que essas operaçóes internacionais podem ser essencialmente de dois tipos: para dentro ou inward (importaçóes, compra de tecnologia, contratos de franquias de empresas estrangeiras e obtenção de licenças de fabricaçáo) e para fora ou outward (exportações, concessão de licenças/franquias e investimento direto no exterior). 
Ansoff e McDonnell (1993) apontam as intenções mais almejadas pelas organizaçōes por meio da internacionalização, como: o crescimento no volume de negócios, a melhoria da rentabilidade a curto e longo prazos, a invulnerabilidade futura e o equilíbrio da carteira estratégica. Tais intençóes corroboram o entendimento de Kobrin (1991) de que a atuação de uma empresa em diferentes países impacta positivamente sua competitividade. $\mathrm{O}$ autor esclarece que seu ingresso em novos mercados pode reforçar seu domínio do mercado interno, além de descortinar oportunidades em outros mercados.

No caso brasileiro, o processo de internacionalização parece estar associado à conjuntura econômica do país. Conforme literatura sobre o tema, as crises econômicas domésticas e internacionais geram impactos nos investimentos realizados pelas multinacionais brasileiras. Estudos da Fundação Dom Cabral (FDC, 2020) revelam que em ambientes pouco propícios à internacionalização - com moeda fraca e/ou escassez de crédito no cenário nacional - são poucas as empresas que investem em outras economias ou que se expandem de forma significativa. Entretanto, a condição oposta, configurada pelo aumento da oferta de crédito, acompanhado de aumento da demanda global e da ampliação da capacidade produtiva das empresas, descortina-se considerável oportunidade para o alcance de mercados globais. A edição especial daquela pesquisa aponta que o percentual de empresas internacionalizadas (com subsidiárias próprias ou franquias) ainda denota pouca representatividade, ao atingir apenas $0,01 \%$ das empresas brasileiras, que corresponde a aproximadamente 500 empresas, segmentadas espacialmente em 89 países. Náo obstante esse percentual ainda seja pequeno, a análise histórica do processo de internacionalização das empresas brasileiras revela uma evolução, seja no número de empresas, seja no grau médio de internacionalização, que em 2006 atingia a faixa de 12,9\% e em 2019 alcançou o nível de $21,6 \%$.

Goulart et al. (1994) apontam quatro estratégias de internacionalização que parecem advir da atuação precípua da organização. A primeira decorre da evolução da capacidade de exportação da organização; a segunda, como consequência das vantagens competitivas já adquiridas no mercado doméstico; a terceira, impulsionada pela busca de competitividade tecnológica; e a quarta, como decorrência de exposição internacional. Fleury, Fleury, Borini, Oliveira Junior e Reis (2015) asseveram que a motivação para a internacionalizaçáo está associada a uma espécie de 'intento estratégico', conceito proposto por Hamel e Prahalad (1989), que por alguma razão, justifica o esforço empreendido pela organização para se tornar internacional.

Nesse contexto, admitem como fatores motivadores: o acesso a mercados/novos mercados; o acesso à tecnologia e conhecimento; o acesso a recursos em busca de maior eficiência; e eficácia e proximidade a clientes, fornecedores e parceiros. Denberg e Gomes (2011) elencam os motivos mais comuns a impelirem as organizaçóes a se tornarem internacionais (p. 81), conforme literatura (Porter, 1986; Czinkota, Honkainen, Moffet \& Moynihan, 1998; Kotler, 2000):

i. Estratégia de defesa - Ocorre quando uma empresa encontrada situada em um determinado país, com operação local, e tem seu mercado invadido por outra empresa estrangeira, e, assim, decide contraatacar a concorrente em seu mercado de origem;

ii. Quando uma empresa percebe que suas operaçóes locais não são mais suficientes para a obtenção de economias de escala e, assim, decide aumentar suas economias de escala operando em outros 
mercados, ação essa que pode também servir de base como estratégia defensiva ou ofensiva;

iii. Diversificação - A empresa percebe como risco o fato de estar somente em um mercado e, para diminuir sua dependência em relação a esse único mercado, decide operar em outros mercados;

iv. Os clientes da empresa estáo se internacionalizando e a empresa resolve acompanhá-los na internacionalização como mecanismo de expansão de suas atividades e também como forma de manter sua participação nessas empresas, pois, caso não o faça, corre o risco de perder esses clientes para outros fornecedores; e

v. Oportunidade de mercado - a empresa percebe na internacionalização, isto é, em avançar para novos mercados, uma oportunidade de realização de maiores lucros.

Do arcabouço teórico de Keegan e Green (1999) resgata-se a descrição dos principais mecanismos adotados pelas organizaçóes quanto à forma de entrar em novos mercados, seja pela proximidade cultural, geográfica ou por questóes de oportunidade de mercado. Lopes e Gomes (2013) apresentam uma consolidaçáo de algumas classificaçóes para as empresas internacionalizadas (Canals, 1994; Bartlett \& Goshal, 1992; Dyment, 1987; entre outros), retratada na tabela 2.

Ainda nessa temática, Dyment (1987) destaca a diferença entre o conceito de multinacional, empresa tradicional e empresa global. Para o autor, o termo 'multinacional' refere-se às organizaçóes que atuam em vários países com base em estratégias e estruturas organizacionais locais. A empresa global, por sua vez, diferencia-se por adotar uma estratégia coordenada que inclui todos os países em que atua, o que a permite obter uma vantagem competitiva. Transcorrida essa breve revisão de literatura sobre o processo de internacionalização de empresas, torna-se oportuna a apresentação das premissas teóricas que sustentam tal processo, as quais serấo retratadas na tabela 3 , a partir de duas correntes: a econômica ou eclética; e a comportamental ou organizacional.

\section{Tabela 2. Classificação das empresas} internacionalizadas

\begin{tabular}{|c|c|}
\hline $\begin{array}{c}\text { Empresa } \\
\text { exportadora }\end{array}$ & \multicolumn{1}{c|}{$\begin{array}{c}\text { Fase inicial do processo de } \\
\text { internacionalizaçáo. Geralmente, as } \\
\text { unidades operacionais ficam no país de } \\
\text { origem. }\end{array}$} \\
\hline $\begin{array}{c}\text { Empresa } \\
\text { multinacional }\end{array}$ & $\begin{array}{l}\text { Pretende explorar as vantagens competitivas } \\
\text { diversificando atividades em outros países. } \\
\text { Tem como objetivo a reproduçáo quase } \\
\text { exata da matriz em cada uma das filiais no } \\
\text { exterior, criando forte presença local através } \\
\text { de sensibilidade e receptividade às diferenças } \\
\text { nacionais; }\end{array}$ \\
\hline Empresa global & $\begin{array}{l}\text { O objetivo é adquirir vantagem competi- } \\
\text { tiva em termos de custos e receitas através } \\
\text { de operaçós centralizadas em escala global, } \\
\text { sendo que suas atividades críticas devem se } \\
\text { concentrar em um ou poucos países; }\end{array}$ \\
\hline Empresa & $\begin{array}{l}\text { É a empresa que combina adequadamente } \\
\text { uma máxima eficiência econômica, capaci- } \\
\text { dade de responder a mercados locais e fle- } \\
\text { xibilidade para transmitir as experiências de } \\
\text { outros países para toda a organização; }\end{array}$ \\
\hline transnacional
\end{tabular}

Fonte: Elaborado por Lopes e Gomes (2013), com base em Bartlett e Ghoshal (1992), Canals (1994) e Dyment (1987).

\subsection{Impactos da internacionalizaçáo sobre os sistemas de controle gerencial}

As Multinacionais são caracterizadas pela dispersão geográfica, onde a organização sede e as subsidiárias encontram-se localizadas em países diferentes. Nesse contexto, operam e interagem com redes de negócios do país anfitriáo, incluindo fornecedores e compradores locais, bem como sob a jurisdição do arcabouço jurídico e contexto econômico do mesmo país (Ghoshal \& Bartlett, 1990). 


\section{Tabela 3. Abordagens do processo de Internacionalizaçáo de empresas}

\begin{tabular}{|c|c|}
\hline & Abordagem Econômica ou Eclética \\
\hline P. & em, destaca-se a Teoria do Ciclo do Produto, a Teoria da Internalização e o Paradigma Eclético. \\
\hline $\begin{array}{l}\text { Perspectiva } \\
\text { da Teoria da } \\
\text { Internalizaçấo }\end{array}$ & $\begin{array}{l}\text { Fina e Rugman (1996) salientam que "os teóricos da internalização sugerem que o investimento direto no exterior } \\
\text { ocorre quando os benefícios da internalizaçáo superam os custos" (p.200). Nesse contexto, Denberg e Gomes } \\
\text { (2011) esclarecem que a teoria da internalização entende que as falhas de mercado - como custos de informaçấ, } \\
\text { oportunismo e especificação de ativos - originam as condiçóes propícias a que uma empresa multinacional utilize } \\
\text { o investimento direto como modo de entrada no exterior. }\end{array}$ \\
\hline $\begin{array}{l}\text { Perspectiva da } \\
\text { Teoria do Ciclo do } \\
\quad \text { Produto }\end{array}$ & $\begin{array}{l}\text { Proposta por Vernon }(1966,1979) \text {, enfatiza o potencial do mercado consumidor como fundamento para explicar } \\
\text { a internacionalizaçáo das empresas. Assim, depois de exploradas as oportunidades e atendida a demanda do mer- } \\
\text { cado no país de origem, a empresa passaria a exportar para outros países e assim daria um novo recomeço ao ciclo } \\
\text { de vida do produto (Bueno \& Domingues, 2011). }\end{array}$ \\
\hline & $\begin{array}{l}\text { Desenvolvida por Dunning (1988), com base nos princípios de economia, nos princípios da Teoria dos Custos de } \\
\text { Transaçáo (Williamson, 1981) e, ainda, na Teoria da Internalizaçáo. }\end{array}$ \\
\hline $\begin{array}{l}\text { Perspectiva do } \\
\text { Paradigma Eclético } \\
\text { da Produçáo }\end{array}$ & $\begin{array}{l}\text { Revela-se um modelo conceitual para internacionalização que busca explicar a amplitude, a forma e o padrão da } \\
\text { produçáo internacional, a partir de três tipos de vantagens: as inerentes à propriedade das firmas relativas à pro- } \\
\text { dução no exterior; a propensão a internalizar mercados; e a atratividade da localizaçáo da produçấo no exterior. }\end{array}$ \\
\hline & $\begin{array}{l}\text { Na concepçáo de Dunning (1988), ao atuar no mercado externo, a empresa pode manter suas atividades internas, } \\
\text { sem assumir as transaçôes ineficientes do mercado estrangeiro, unindo as vantagens da manutençấo da proprie- } \\
\text { dade do conhecimento interno. }\end{array}$ \\
\hline
\end{tabular}

\section{Abordagem Comportamental ou Organizacional}

Possui como exponencial a escola nórdica, com destaque para a Universidade de Uppssala, a quem está associado o Modelo de Uppsala.

\begin{tabular}{|c|c|}
\hline \multirow{11}{*}{ Modelo de Uppssala } & $\begin{array}{l}\text { Segundo Bueno e Domingues (2011), essa escola assume a existência de informaçóes disponíveis a respeito das } \\
\text { variáveis envolvidas, às quais o gestor consegue acessar e, a partir de então, escolher não só o mercado-alvo, mas } \\
\text { também, a forma de entrar nele, além dos principais desafios que irá encontrar. }\end{array}$ \\
\hline & Denberg e Gomes (2011) salientem que para esta escola: \\
\hline & $\begin{array}{l}\text { A internacionalização é um processo de ajustes incrementais às condiçóes variáveis da empresa e do seu } \\
\text { ambiente, apresentando os seguintes estágios de envolvimento internacional: }\end{array}$ \\
\hline & Estágio I - não existência de atividades regulares de exportação; \\
\hline & Estágio II - exportação feita por intermédio de representantes independentes; \\
\hline & Estágio III - estabelecimento de uma subsidiária de venda no exterior; \\
\hline & Estágio IV - unidades de operações no exterior (produção, por exemplo) (p. 83). \\
\hline & $\begin{array}{l}\text { De acordo com Johanson e Vahlne (1990), "essa sequência de estágios indica o comprometimento crescente de } \\
\text { recursos com o mercado. Ela indica, ainda, as atividades correntes (operaçóes) que se diferenciam em razão da } \\
\text { experiência acumulada" (p. 13). }\end{array}$ \\
\hline & $\begin{array}{l}\text { Asseveram, ainda, que as pesquisas inerentes a este modelo apontem o desenvolvimento das operaçóes internacio- } \\
\text { nais paulatinamente até a realização de investimentos maiores em produção no exterior. }\end{array}$ \\
\hline & $\begin{array}{l}\text { Melo e Andreassi (2012) salientam uma característica relevante defendida por este conceito que se refere à distân- } \\
\text { cia psíquica em face da proximidade ou náo da cultura, de valores, práticas gerenciais, crenças e educaçáo vigentes } \\
\text { nos países para onde se deseja internacionalizar. }\end{array}$ \\
\hline & $\begin{array}{l}\text { Segundo Melo e Andreassi (2012), "estudos empíricos mostram que a propagaçáo internacional das empresas tem } \\
\text { início nos mercados geográficos e culturais mais próximos do mercado doméstico" (p. 73). }\end{array}$ \\
\hline
\end{tabular}

Fonte: Elaborado pelos autores com base em Gomes e Salas (2001, p. 57-60). 
O processo de internacionalização, bem como sua extensão, impele às organizaçóes o desafio de transferir o Controle de Gestáo para além das fronteiras nacionais (Harrison \& Mckinnon, 1999). O ambiente de atuação daquelas empresas é, portanto, permeado pela alta complexidade. Além de coordenar diferentes divisôes de negócios, aquelas organizaçôes precisam superar distâncias geográficas e culturais, bem como se adaptar ao ambiente do país anfitriáo (Merchant \& Van der Stede, 2017).

Segundo Dyment (1987), a gestáo das empresas globalizadas deve ser bem diferente da gestão de empresas nacionais ou multinacionais. $\mathrm{O}$ autor salienta que o controle gerencial inerente a uma organização global deve permitir à administração central a coordenação da organização em todos os países onde ela opera. Já em uma organização multinacional, o sistema de controle deve se ajustar ao contexto de negócios separados, podendo variar as estratégias de um país para outro, bem como, contemplando a adoção de relatórios de controle que subsidiem a necessidade da administração local.

Prahalad e Doz (1993) ressaltam que a partir do momento em que as subsidiarias crescem e se tornam mais autônomas em relação aos recursos estratégicos, deparam-se com um problema no sistema de controle gerencial de empresas globalizadas, o qual está refletido na redução da capacidade de a organização central controlar as estratégias das subsidiárias (citados por Denberg \& Gomes, 2011).

No tocante às organizaçóes transnacionais, Bartlett e Ghoshal (1992) asseveram que a administração deve, primeiramente, responder às mudanças ambientais com base nos recursos estratégicos disponíveis. Posteriormente, deve empreender uma coordenação flexível, capaz de gerenciar a complexidade. Por fim, deve estabelecer mecanismos que desenvolvam um maior comprometimento com os propósitos da organização, tanto da parte dos gestores, quanto do lado dos demais funcionários.

Em sentido diverso daquele autor, Anthony e Govindarajan (1998) entendem que os processos de planejamento e controle adotados por uma empresa multinacional devem ser, a priori, semelhantes ao utilizado por uma empresa nacional. Entretanto, neste caso, deve ser especialmente projetado para atender às peculiaridades do contexto multinacional.

Merchant (1998) entende o controle de uma organização multinacional como mais complexo do que o de uma organização nacional, por cindo razóes: a estrutura tridimensional das organizaçôes multinacionais (dimensôes funcionais, linha de produtos e extensão geográfica); a necessidade de determinar preços de transferência internacional; o problema de câmbio; a limitação do uso de controles de ação em razão da dificuldade da administração realizar um julgamento adequado, em face da alta assimetria; e as distâncias e diferentes idiomas e fusos horários que dificultam visitas frequentes e a comunicação entre os gestão central e unidades externas. No tocante aos problemas de ordem cultural frequentemente encontrados, Denberg e Gomes (2011) destacam o idioma, os costumes, as práticas de negócios, as regras e as leis. Os autores reiteram que esses problemas podem variar de forma significativa de um país para outro, tornando complexa a tomada de decisóes sem considerar tais peculiaridades dos negócios locais e suas incertezas.

Anthony e Govindarajan (2008) destacam, entre os problemas que circundam os sistemas de controle gerencial adotados no exterior, a política de preços de transferência e as taxas de câmbio. Sobre o primeiro, 
ressaltam que, a forma como for constituído impactará a avaliação de desempenho das unidades operacionais instaladas no exterior. No tocante às taxas de câmbio, há consenso de que as unidades instaladas no exterior não devam ser responsabilizadas pelos resultados obtidos como decorrência da conversáo das demonstrações para a moeda da empresa do país de origem (Anthony \& Govindarajan, 2008; Maciariello \& Kirby, 1994; Merchant, 1998). Todo o exposto corrobora a relevância do controle gerencial em ambiente internacionalizado, ao passo que, possivelmente, a decisão de a organização internacionalizar suas atividades impactará seu sistema de controle gerencial.

\section{Metodologia}

O presente estudo consiste de uma pesquisa qualitativa de natureza exploratória-descritiva, que adotou como estratégia o estudo de caso. Quanto aos seus objetivos, revela-se descritiva, pois a decorrência da análise do caso consiste de uma descrição dos impactos observados no controle gerencial da empresa, em consequência de seu processo de internacionalização (Gil, 2002).

O caráter exploratório, por sua vez, é observado a partir do levantamento das informaçóes, documentos e material audiovisual, que contêm o arcabouço teórico necessário e suficiente ao aprofundamento do conhecimento sobre o processo de controle gerencial da empresa Localiza e de seu processo de internacionalização, com vistas à análise que encerra o propósito do artigo (Araújo, 2006). Creswell (1997) define o estudo de caso como: "a exploração de um sistema limitado ou um caso (ou múltiplos casos) [...] que envolve coleta de dados em profundidade e múltiplas fontes de informação em um contexto" (p. 61). Segundo Gomes (2012), "se o caso se tratar da descrição de uma empresa, torna-se importante conhecer o contexto social no qual está inserida. O período, concorrência, tendências etc. são variáveis importantes a serem consideradas na análise" (p. 15-16). Conforme se depreende, tal procedimento metodológico revela-se ideal ao estudo, já que permite a coleta de dados em profundidade sobre a empresa objeto desta pesquisa.

No tocante aos instrumentos de coleta de dados, a pesquisa incluiu o levantamento da documentação pública divulgada na página institucional da empresa Localiza, especialmente no sitio 'ri.localiza' (relaçóes com investidores), donde foram extraídas informaçóes sobre a história da empresa, sua criação e expansão, passando pela organizaçáo interna, estrutura organizacional, sistema de controle de gestáo e governança, alcançando, ainda o processo de internacionalizaçáo de suas atividades, relatórios de desempenho, documentação contábil, práticas de câmbio e política de sustentabilidade.

Complementarmente, foram coletados dados em sites de gestão de negócios e especializados em internacionalização de empresas, de onde foram extraídas informaçóes mais recentes sobre a empresa Localiza, incluindo o processo de fusão com a empresa Movida, que posteriormente fora referendado em Fato Relevante divulgado pela empresa.

A pesquisa bibliográfica foi realizada em bases de dados de periódicos acadêmicos especializados, como SPELL, SCIELO, Google Acadêmico, Portal de periódicos da Capes, não exclusivamente, além de obras impressas de autores de referência para o tema em estudo. Para tanto, foram utilizados como descritores os termos 'Controle Gerencial' e 'Internacionalização’, a fim de levantar o arcabouço teórico substancial necessário à identificação e análise dos dados coletados, conforme propósito desta 
pesquisa. Foram coletados, ainda, estudos da Fundação Dom Cabral, a qual dedica desde o ano de 2006, um levantamento anual sobre o grau de internacionalização, também conhecido como Ranking das Multinacionais Brasileiras.

Por fim, a coleta de dados conjuga duas entrevistas, as quais consistem de dados secundários, já que não foram empreendidas por estes autores, mas sobre as quais, obteve-se acesso. A primeira entrevista, realizada em agosto de 2009, pela Press Comunicação Empresarial, com o diretor de Franchising da Localiza, à época, Bruno Andrade, a qual foi disponibilizada no site 'suafraquia.com'; e a segunda entrevista, realizada em agosto de 2020, pela Genial Investimentos, com o CEO da Localiza, Eugênio Mattar, cuja realização foi transmitida ao vivo por meio de live e, posteriormente, disponibilizada no YouTube.

O levantamento dos dados conforme exposto acima, foi realizado por estes autores no período de julho de 2020 a janeiro de 2021, com o fito de incluir as informaçōes mais recentes e que pudessem subsidiar o estudo do caso. A análise dos dados coletados, por sua vez, a partir do robusto material coletado, também foi realizada por ambos autores, sendo organizada em etapas que podem ser elencadas, como: uma fase inicial de conhecimento sobre o histórico de surgimento e contexto social no qual a Localiza está inserida; em seguida, foi analisado o período cronológico, a evolução do negócio, incluindo as tendências, o sistema de controle gerencial, bem como as decisóes de crescimento e internacionalização; e por fim, foram analisados os impactos decorrentes do processo de internacionalizaçáo no sistema de controle gerencial da empresa. Todo o arcabouço coletado subsidiou a realizaçáo do estudo de caso em profundidade da empresa Localiza, conforme intentado.

\section{Análise de dados}

A Localiza é uma empresa especializada em aluguel de carros no Brasil e na América Latina. Possui 529 agências (dados referentes ao $2^{\circ}$ trimestre de 2020), presentes em sete países: Brasil, Argentina, Chile, Colômbia, Equador, Paraguai e Uruguai. Sua plataforma de negócios integrada contempla quatro Divisões de Negócios, as quais são síncronas: Aluguel de Carros, Aluguel de Frotas, Franchising e Seminovos.

A Companhia foi criada em 1973, na cidade de Belo Horizonte (MG), com uma agência que contava com 6 carros (Fusca) usados e financiados. Iniciou suas atividades com uma empresa familiar, a partir da uniáo de quatro irmãos: dois irmãos da família Mattar e dois irmãos da família Brandão Resende. No final da década de 70, a empresa alcançava onze capitais. Em 1981, tornou-se a líder de mercado no seguimento 'Aluguel de Carros', em número de agências. Em 1984, em resposta à crise da dívida externa da época, adotou a estratégia de Franchising, em âmbito nacional, como forma de expandir sua rede. O licenciamento das 6 primeiras franqueadas foi mediado pela Controlada Localiza Franchising.

Em 1991, a empresa vislumbra a oportunidade de vender seus carros seminovos diretamente ao consumidor final. Essa modalidade de venda permitiu à empresa reduzir seus custos de depreciação e gerar receita para a renovação de sua frota de aluguel - assim surgiu o negócio de 'Seminovos'. Em 1992, como estratégia para contornar as dificuldades do mercado interno, a empresa Localiza inicia seu processo de internacionalização: as franquias passaram a fazer parte da estratégia de internacionalização das operaçóes - a empresa validava o seu know-how e ampliava sua presença na América do Sul.

Contabilidad y Negocios (16) 31, 2021 / e-ISSN 2221-724X 
A Divisão Localiza Franchising é considerada parte essencial do modelo integrado de negócios da Plataforma Localiza. Retrata a Divisão responsável por desenvolver novos mercados e tem como objetivo expandir a presença da empresa no Brasil e no Exterior. A orientação dos negócios está sustentada na oportunidade empresarial. Para tanto, possui como missão a contribuição para o sucesso dos franqueados, por meio da transferência do know-how já adquirido. Dentre os princípios que regem a Franchising, pode-se destacar a valorizaçáo do cliente, o reconhecimento ao desempenho dos colaboradores, o comportamento ético, o zelo pela imagem da empresa; a busca pela excelência e a agregação de valor à marca. Atualmente, a Localiza é uma empresa especializada em franchising e destacou-se como a franquia que mais esteve presente nas posições de liderança do Ranking FDC de Internacionalização de Franquias (no período da pesquisa, de 2011 a 2018), com 7 posiçóes de pódio, das quais 5 vezes, na primeira colocação. É a maior locadora de veículos da América do sul, com uma frota de 225.870 veículos e 429 agências.

Conforme último relatório institucional divulgado pela empresa (relativo ao terceiro trimestre do ano de 2020), a Divisão Localiza Franchising contava com 11.757 carros, distribuídos em 75 agências no exterior, além de 97 agências no Brasil. Sua atuação no exterior não revela um direcionamento da empresa nesse sentido. Conforme pode-se observar, a empresa contava com 70 agências no exterior em 2015 e 75 no 3T 2020 - oscilando para mais e para menos ao longo do tempo, sem grandes evoluçóes.

Observa-se, contudo, uma tendência de reorientação da expansão. Apesar de atribuir à Divisão Franchising a missão de expansão dos mercados e da marca, a recente divulgação da fusão da empresa Localiza com a empresa Unidas, que resultará em uma frota combinada de cerca de 470 mil carros, aponta para uma nova direção. Segundo Fato Relevante divulgado pela Localiza em 8 de outubro de 2020, sobre a 'Combinaçáo dos Negócios da Localiza e da Unidas’, a incorporação proposta é estratégica devido à complementariedade dos negócios das Companhias - que, segundo informado, deverá promover o aproveitamento de ganhos de escala, sinergias e aumentos de eficiência na Companhia Combinada. Tal diversificação já é observada pela empresa Localiza e foi responsável pela redução dos impactos decorrentes da Pandemia do COVID-19.

A Companhia integra o Mercado B3 e para tanto adota os mais elevados padróes de governança. Possui um Conselho de Administração profissional. Adicionalmente, foi uma das ganhadoras do Prêmio Troféu Transparência ANEFAC 2019, pela qualidade de suas Demonstraçóes Financeiras. Atualmente, a empresa é gerida por um Presidente, um Conselheiro e mais quatro conselheiros independentes. Eugênio Pacelli Mattar, um dos sócios fundadores da empresa, compóe o Conselho de Administração, como conselheiro, além de ser o chief executive officer (CEO) da Localiza.

Ainda no tocante à governança, a empresa possui Comitês internos, subordinados ao Conselho de Administração (Comitê de Auditoria, Gestão de Riscos e Compliance, Comitê de Gente e Remuneração e Comitê de Governança), além de outros subordinados ao CEO, bem como o Comitê de Divulgação. A Diretoria da empresa é composta pelo Diretor Presidente - o CEO -, pelo Diretor de Finanças e de Relaçóes com Investidores e por mais sete Diretores Executivos. A questão da sustentabilidade revelou-se marcante a partir de 2017, quando se tornou uma intenção estratégica materializada na assinatura o Pacto Global. A criação do Comitê de Sustentabilidade em 2018, entre outras iniciativas posteriores, reforça tal orientação. A Localiza mantém a orientação para a inovação, 
incorporando soluçóes digitais pioneiras para melhorar a experiência do cliente. Tal orientação foi referendada ao ser declarada a Top of Mind player com liderança em tecnologia, no ano de 2020.

\section{Discussão}

O processo de internacionalização da Localiza, a partir de concessão de franquias, caracteriza uma internacionalização para fora (Barreto \& Rocha, 2003). Alinhado ao pensamento de Ansoff e McDonnell (1993), identifica-se os seguintes impulsionadores para a internacionalização da empresa: o crescimento no volume de negócios, a invulnerabilidade futura e o equilíbrio da carteira estratégica.

Verifica-se no discurso do Diretor de Franchising em 2009 (em entrevista realizada em 2009 pela Press Comunicação Empresarial, no site 'Sua Franquia') que a grande motivação para a extensão das franquias do país sede para outros países foi a 'oportunidade de negócio', conforme apresentado por Denberg e Gomes (2011) e literatura sobre o tema (Porter, 1986; Czinkota et al., 1998; Kotler, 2000). Segundo Andrade (2009), a empresa almejava, ainda, fortalecer a marca regionalmente, ao passo que no Brasil, a Localiza já havia conquistado seu espaço.

A concepção de que a atuação da empresa em diferentes países agiria como um elemento de impacto positivo na competitividade da rede de negócios (Kobrin, 1991) revelou-se aplicável no caso localiza. Após dez anos de internacionalização, a Companhia percebia o grande valor de sua expansão internacional através da franchising, ao passo que tais franquias geravam receitas adicionais e reforçavam a imagem da Localiza como um player no continente.

Quanto à forma de entrada no mercado internacional, a Localiza classifica-se como uma empresa transnacional.
Conforme dados da empresa, busca combinar da melhor forma a máxima eficiência econômica, capacidade de responder a mercados locais e a flexibilidade para transmitir seu now how para toda a organização. No tocante à premissa teórica associada ao processo de internacionalização em estudo, entende-se por uma forte aproximação à abordagem da escola de Uppssala. No contexto dessa Escola, a Localiza permanece no Estágio 2 de internacionalização, onde sua atuação ainda é mediada por representantes, retratados pelos franqueados.

Outro aspecto marcante, vinculado à escola de Uppssala, reside no conceito da distância psíquica, bastante aparente nas falas dos gestores. Conforme relatado, o processo de internacionalização da Localiza iniciou-se com o estabelecimento das primeiras franquias na cidade de Buenos Aires, na Argentina, estendendo-se, posteriormente a outros países da América do Sul. A escolha pelo continente sul-americano, de acordo com o Diretor de Franquias Bruno Andrade, atribuiu-se à proximidade geográfica e cultural e também à carência e pulverização do mercado verificada naqueles países: "Detectamos que havia espaço para o crescimento e que uma marca brasileira poderia ser muito bem vista”.

Em face das características de controle analisadas, observam-se traços marcantes do controle burocrático. Não obstante a cultura organizacional seja orientada para resultados extraordinários, a estrutura de controle revela-se bastante estruturada, bem como as decisóes igualmente centralizadas. Conforme proposto por Denberg e Gomes (2011), sobre a necessidade de delegação do controle à medida que as operações das organizaçôes crescem, tal descentralização é percebida quando da atribuição da gestão a um Conselho de Administração. Observa-se, contudo, a atuação de um sócio fundador nas decisões mais relevantes da organização, seja como CEO, Diretor Presidente ou Conselheiro.

Contabilidad y Negocios (16) 31, 2021 / e-ISSN 2221-724X 
No tocante ao processo de internacionalização, verifica-se que, diferentemente das agências de franquias brasileiras, que são geridas por uma controlada, as agências alocadas no exterior são administradas diretamente pela localiza. Conforme proposto por Bartlett e Ghoshal (1992), ao retratar a administração em empresas transnacionais, verifica-se que a Localiza se utiliza de todo seu arcabouço estratégico e now how adquiridos e os disponibilizam para apropriação pelas agências franqueadas no exterior. Posteriormente, estabelece as bases de gestão, mantendo centralizadas as decisões estratégicas inerentes a essas franquias, entretanto, permitindo que a gestão local ocorra de forma descentralizada.

A gestão da Divisão Franchising está sustentada no treinamento e capacitação da equipe técnica, com emprego de moderna tecnologia da informação e Sistema de autogestão pelo franqueado. No tocante às estratégias de marketing, são definidas nacionalmente, sendo as açôes de marketing, publicidade e comunicaçôes definidas localmente. Como suporte, a empresa conta com o Plano anual de desenvolvimento dos franqueados. Por fim, estabelece uma série de mecanismos para a manutenção dos padrões de excelência da empresa e para desenvolvimento de maior comprometimento com os propósitos da organização, seja por gestores, ou da parte dos demais funcionários.

Por fim, no tocante às taxas de câmbio, os franqueados que operam fora do Brasil pagam a taxa de integração e royalties mensais com base em taxas variáveis que dependem das condiçóes do mercado de cada país. Tal prática revela-se alinhada ao entendimento de que as unidades instaladas no exterior não devam ser responsabilizadas pelos resultados obtidos como consequência da conversão das demonstrações para a moeda da empresa do país de origem (Anthony \& Govindarajan, 2008; Maciariello \& Kirby, 1994; Merchant, 1998).

\section{Consideraçóes finais}

O estudo do caso da empresa Localiza teve como objetivo analisar os impactos do processo de internacionalização em seu Sistema de Controle de Gestão. A respeito dos impactos sobre o controle gerencial, pode-se depreender que o sistema de controle de gestão da empresa foi substancialmente aperfeiçoado para incluir a governança corporativa, bem como alcançar os propósitos de crescimento da empresa.

Observou-se características do controle burocrático, com estrutura de controle estruturada, decisóes igualmente centralizadas, além da atuação marcante de um de seus sócios fundadores. A empresa se utiliza de todo seu arcabouço estratégico e now how adquiridos e os disponibilizam para apropriação pelas agências franqueadas no exterior. Posteriormente, estabelece as bases de gestão, mantendo centralizadas as decisóes estratégicas inerentes a essas franquias, entretanto, permitindo que a gestáo local ocorra de forma descentralizada. As taxas de câmbio, por sua vez, não foram identificadas como um problema, já que os pagamentos dos franqueados no exterior são mediados com base em taxas variáveis inerentes às condições do mercado de cada país.

Conclui-se, sobretudo, que a internacionalização não promoveu mudanças significativas no sistema de controle gerencial da empresa, em consonância com literatura náo majoritária sobre o tema. Entretanto, observou-se grandes mudanças no controle gerencial a partir do processo de expansão da organização como um todo, as quais, notadamente, impactaram o desempenho das franquias internacionais. Por fim, sugere-se a continuidade de estudos como este, seja como forma de geração de conhecimento sobre os impactos da internacionalização no controle gerencial, seja como possibilidade de retificar ou ratificar se a 
concepçáo outrora não majoritária permanece nossa condição, seja para identificar possíveis correlaçóes entre o processo de internacionalização e os impactos dele decorrente no controle gerencial.

\section{Referências}

Andrade, B. (2009). Localiza é uma das empresas mais internacionalizadas do Brasil [Gravação de vídeo]. Recuperado de https://www.suafranquia.com/noticias/ servicos-automotivos/2009/08/localiza-e-uma-dasempresas-mais-internacionaliza das-do-brasil/ [Consulta: 30 de novembro de 2020].

Ansoff, H. I., \& McDonnel, E. J. (1993). Implantando administração estratégica. São Paulo: Atlas.

Anthony, R.N. (1965). Planning and Control Systems: Frame Works for Analysis. Boston: Harvard Business School Press.

Anthony, R. N., \& Govindarajan, V. (1998). Management Control Systems. Columbus: McGraw-Hill/Irwin.

Anthony, R. N., \& Govindarajan, V. (2008). Sistema de Controle Gerencial. São Paulo: McGraw-Hill.

Araújo, C. A. (2006, jan.-jun.). Bibliometria: evolução histórica e questôes atuais. Em Questão, 12(1), 11-32.

Barreto, A., \& Rocha, A. (2003). A expansão das fronteiras: brasileiros no exterior. En A. Rocha (Org.), As Novas Fronteiras: a multinacionalização das empresas brasileiras (pp. 29-76). Rio de Janeiro: Mauad.

Bartlett, C. A., \& Ghoshal, S. (1992). Gerenciando Empresas no Exterior: A Solução Transnacional. São Paulo: Makron Books.

Bueno, J. M., \& Domingues, C. R. (2011). Internationalization Strategies of Emerging Companies: A Comparative Study of Brazilian Cases. Future Studies Research Journal: Trends and Strategies, 3(2), 57-83.

Canals, J. (1994). La internacionalización de la empresa. Madrid: Mcgraw-Hill.
Creswell, J. W. (1997). Qualitative Inquiry and Research Design: Choosing Among Five Traditions. Thousand Oaks: Sage.

Czinkota, M. R., Ronkainen, I. A., Moffet, M. H., \& Moyniham, E. O. (1998). Global Business. Forth Worth: The Dryden Press.

Denberg, M. W. S., \& Gomes, J. S. (2011). Impactos ocasionados pela internacionalizaçáo em empresas brasileiras: um estudo de caso múltiplo. Contabilidade, Gestão e Governança, 14(3), 77-99.

Dunning, J. H. (1988, Spring). The Eclectic Paradigm of International Production: A Restatement and Some Possible Extensions. Journal of International Marketing Business Studies, 19(1), 1-31. https://doi.org/10.1057/ palgrave.jibs. 8490372

Dunning, J. H. (2000). The Eclectic Paradigm as an Evolve for Economic and Business Theories of MNE Activity. International Business Review, 9(2), 163-190. https:// doi.org/10.1016/S0969-5931(99)00035-9

Dyment, J. J. (1987, Spring). Strategies and Management Controls for Global Corporations. The Journal of Business Strategy, 7(4), 20-26. https://doi.org/10.1108/ eb039172

Ferreira, D., Cavalcanti Neto, S., \& Gomes, J. S. (2014). Internacionalização de empresas: Uma análise bibliométrica da produção científica dos últimos cinco anos. Revista Magistro, 9(1), 1-23.

Fina, E., \& Rgman, A. N. (1996). A Test of Internalization Theory: The Upjohn Company. Management International Review, 36(3),199-223.

Flamholtz, E. (1996). Effective Organizational Control: A Framework, Applications, and Implications. European Management Journal, 14(6), 596-611. https://doi. org/10.1016/S0263-2373(96)00056-4

Fleury, A., Fleury, M. T. L., Borini, F. M., Oliveira Junior, M. M., \& Reis, G. G. (2015). Gestão estratégica das multinacionais brasileiras. São Paulo: USP/FGV.

Contabilidad y Negocios (16) 31, 2021 / e-ISSN 2221-724X 
Fundação Dom Cabral (FDC). (2020, May 16). Trajetórias FDC de Internacionalização das Empresas Brasileiras: edição histórica. Recuperado de https://trajetoriasinternacionais.fdc.org.br/wp-content/themes/elision/ img/Trajetorias_de_Internacionalizacao_das_Empresas_Brasileiras_Edicao_Especial.pdf [Consulta: 4 de janeiro de 2021].

Genial Investimentos. (2021). Entrevista com Eugênio Mattar, CEO da Localiza [Gravação de vídeo]. Recuperado de https://www.youtube.com/watch?v=_UDUp5rlAA [Consulta: 30 de novembro de 2020].

Gil, A. C. (2002). Como elaborar projetos de pesquisa. São Paulo: Atlas.

Ghoshal, S., \& Bartlett, C. A. (1990). A corporação multinacional como uma rede interorganizacional. Acad Manag Ver, 15, 603-625.

Gomes, J. S. \& Salas, J. M. A. (2001). Controle de gestão: uma abordagem contextual e organizacional. São Paulo: Atlas.

Gomes, J. S. (2012). O método do estudo de caso aplicado à gestão de negócios: textos e casos. São Paulo: Atlas.

Goulart, L., Arruda, C. A., \& Brasil, H. V. (1994, Out/Nov/ Dez). A evolução na dinâmica de internacionalização. Revista Brasileira de Comércio Exterior, (41), 31-40.

Guerra, T. T. A., \& Senhoras, E. M. (2015). Evolução da internacionalização empresarial brasileira. Boa Vista: Editora da UFRR.

Hamel, G., \& Prahalad, C. K. (1989, May-Jun.). Strategic Intent. Harvard Business Review, 63-76.

Harrison, G. L., \& Mckinnon, J. L. (1999). Pesquisa transcultural em projeto de sistemas de controle de gestão: a revisão do estado atual. Accounting, Organizations and Society, 24(5-6), 483-506. https://doi.org/10.1016/ S0361-3682(97)00048-2

Hofstede, G. H. (1975). Percepções dos outros após um grupo T. The Journal of Applied Behavioral Science, 11(3), 367377. https://doi.org/10.1177/002188637501100308
Johanson, J., \& Vahlne, J. E. (1990). The Mechanism of Internationalization. International Marketing Review, 7(4), 11-24. https://doi.org/10.1108/02651339010137414

Johanson, J., \& Vahlne, J. E. (2009). The Uppsala Internationalization Process Model Revisited: From Liability of Foreignness to Liability of Outsider Ship. Journal of International Business Studies, 40(9), 1411-1431. https://doi.org/10.1057/jibs.2009.24

Keegan, W. J., \& Green, M. C. (1999). Principios de marketing global. São Paulo: Saraiva.

Kobrin, S. J. (1991). An Empirical Analysis of Determinants of Global Integration [Summer Special Issue]. Strategic Management Journal, 12(S1), 17-32. https:// doi.org/10.1002/smj.4250120904

Kotler, P. (2000). Administração de marketing. São Paulo: Prentice-Hall.

Localiza. (2020a). Plataforma de negócios: a companhia. Recuperado de https://ri.localiza.com/a-companhia/ plataforma-de-negocios/ [Consulta: 30 de novembro de 2020].

Localiza. (2020b). Sobre a Localiza: Franchising. Recuperado de https://www.localiza.com/brasil/pt-br/sobre-alocaliza/nossas-empresas/franchising/\#b [Consulta: 30 de novembro de 2020].

Lopes, R. S. S., \& Gomes, J. S. (2013, abr./jun.). O impacto da internacionalização sobre os sistemas de controle gerencial de empresas do setor de indústrias têxtil brasileiro: estudos de casos do segmento de moda feminina. Revista Universo Contábil, 9(2), 06-26.

Lorange, P., \& Morton, M.S.S. (1974). Management Control Systems: A Conceptual Framework (Sloan Working Paper 724-74). Cambridge: MIT Alfred P Sloan School of Management.

Maciariello, J. A., \& Kirby, C. J. (1994). Management Control Systems: Using Adaptive Systems to Attain Control. Upper Saddle River: Prentice Hall.

Macintosh, M. B. (1994). Management Accounting and Control Systems: An Organizational and Behavioral Approach. Nova York: John Wiley \& Sons. 
Malmi, T., \& Brown, D. A. (2008). Sistemas de controle de gestão como um pacote - oportunidades, desafios e direções de pesquisa. Management Accounting Research, 19(4), 287-300. https://doi.org/10.1016/j. mar.2008.09.003

Melo, P., \& Andreassi, T. (2012). Franquias brasileiras: Estratégia, empreendedorismo, inovação e internacionalização. São Paulo: Cengage Learning.

Merchant, K. A. (1998). Modern Management Control Systems: Text and Cases. Upper Saddle River: PrenticeHall.

Merchant, K. A., \& Van der Stede, W. A. (2017). Sistemas de controle de gestão: medição de desempenho, avaliação e incentivos. Harlow: Pearson.

Porter, M. E. (1986). Estratégia competitiva. Técnicas para análise da indústria e da concorrência. Rio de Janeiro: Campus.
Vernon, R. (1966). International Investment and International Trade in the Product Cycle. The Quarterly Journal of Economics, 80(2), 190-207. https://doi. org/10.2307/1880689

Vernon, R. (1979). The Product Cycle Hypothesis in a New International Environment. Oxford Bulletin of Economics \& Statistics, 41(4), 255-267. https://doi. org/10.1111/j.1468-0084.1979.mp41004002.x

Williamson, O. (1981). The Economics of Organization: The Transaction Cost Approach. The American Journal of Sociology, 87(3), 548-577. https://doi.org/10.1086/ 227496

Fecha de recepción: 30 de enero de 2021 Fecha de aceptación: 15 de marzo de 2021 Correspondencia: simonefialho@hotmail.com josirsgomes@gmail.com 